IJPSR (2010), Vol. 1, Issue 10

(Review Article)

INTERNATIONAL JOURNAL
PHARMACEUTICAL SCIENCES
REANDARCH

Received on 01 June, 2010; received in revised form 18 August, 2010; accepted 18 September, 2010

DASAPUSHPAM: THE TRADITIONAL USES AND THE THERAPEUTIC POTENTIAL OF TEN SACRED PLANTS OF KERALA STATE IN INDIA

K. Jiny Varghese*, J. Anila, R. Nagalekshmi, S. Resiya and J. Sonu

Department of Pharmacognosy \& Phytochemistry, Amrita School of Pharmacy, Amrita Vishwa Vidyapeetham University, AIMS Healthcare Campus, AIMS Ponekkara P. O., Kochi, Kerala, India

Keywords:

Dasapushpam, Kerala tradition, Sacred plants, Strangury

Correspondence to Author:

K. Jiny Varghese

Department of Pharmacognosy \& Phytochemistry, Amrita School of Pharmacy, Amrita Vishwa Vidyapeetham University, AIMS Healthcare Campus, AIMS

Ponekkara P. O., Kochi, Kerala, India

\begin{abstract}
The Western Ghats of Kerala is famous for its medicinal plant wealth and the tradition of indigenous system of therapy, specifically the Ayurveda. Dasapushpam constitute a group of ten potential herbs which are culturally and medicinally significant to the people of Kerala in India. They are a group of ten herbs with which the ladies decorate their hairs and dance the Thiruvathira Kali on the day of Thiruvathira in the Malayalam month of Dhanu. These plants are therapeutically very active for various diseases and ailments. Many of them are traditionally used from time immemorial. Some of them are scientifically validated for various bioactivities. Still there are lots of possibilities for potential pharmacological activities from these herbs, yet to be explored. This article would give an insight of these ten sacred plants and their properties to further popularise these plants.
\end{abstract}

Available online on www.ijpsr.com 
INTRODUCTION: Plants have been one of the major sources of medicines since the beginning of human civilization. There is a growing demand for plant based medicines, health products, pharmaceuticals, food supplements and cosmetics in the recent days. Kerala is one of the lovely states in India, famous for scenic beaches and serene back waters. Not only the beaches and backwaters but also the entire length and width of Kerala is popular for medical tourism, the indigenous system of therapy, Ayurveda and tourism in Kerala is famous for Ayurveda the ancient system of Indian medicine. The tourism of Kerala to a major extent depends upon the Ayurveda which utilizes various herbal preparations to rejuvenate the body and cure diseases. A fairly good collection of plants over 200 taxa used in Ayurveda include Dasapushpam, ten sacred plants of Kerala tradition and culture.
As per the Tradition of Kerala, the women wears Dasapushpam garland on the head for it was considered sacred plants. In front of the household shrine, the ten sacred plants of dasapushpam were displayed in a gleaming brass plate in the Malayalam month of Karkkidakam (the monsoon season in Kerala) in the olden days. It was also prescribed by the rajavaidyas (doctors for the king) to the ladies to wear these plants on their head, probably due to the medicinal value imparted by them. Several studies were undertaken on different members of Dasapushpam. In this endeavour, we would throw some light to further popularise these sacred plants as these plants are essential as better remedy for various ailments. The plants which are called as Dasapushpam are listed in the following table 1.

\section{TABLE1: DASAPUSHPAM}

\begin{tabular}{cccc}
\hline BOTANICAL SOURCE & MALAYALAM NAME & SANSKRIT NAME & PARTS USED \\
\hline Aerva lanata (L.) Juss.ex.Schult. & Cheroola & Bhadra & Whole plant \\
Biophytum sensitivum (L.) DC & Mukkutty & Viparitha lajjalu & Shole plant \\
Cardiospermum halicacabum L. & Valliyuzhinja & Indravalli & Tuber \\
Curculiogo orchioides Gaertn. & Nilappana & Musali & Leaves \\
Cynodon dactylon (L.) Pers. & Karuka & Durva & Shoots, leaves \\
Eclipta alba (L.)Mant & Kayyunyam & Bringharajan & Shoots, leaves \\
Emilia sonchifolia (L.) DC & Muyalcheviyan & Akhukarni & Whole plant \\
Evolvulus alsinoides (L.) L.var.alsinoides & Vishnukranthi & Lakshmana & Whole plant \\
Ipomea sepiaria Koen. ex Roxb. & Thiruthali & Sahadevi & Whole plant \\
Vernonia cinerea (L.) Less. & Puvamkurunnel &
\end{tabular}

Aerva lanata (L.) Juss. Ex. Schult: this plant is commonly known as polpala, of Amaranthaceae family an important gregarious shrub growing throughout Bangladesh, particularly along waste places in India ${ }^{1}$. It is a branched plant which has white to pale pink spikes of clusters of flowers 1 to 1.5 inches long. The herb is cultivated throughout India, Ceylon, Arabia, Tropical Africa, Java, Philippines. The plant is endowed with various components such as flavonoids, 
alkaloids, Triterpenes, steroids, polysaccharides, tannins, and saponins etc., which possibly contribute its diverse uses in folklore medicine. Several phytoconstituents including 6 alkaloids have been reported earlier. Canthin-6- one, 10methoxycanthin-6-one (methylaervin), 10hydroxycanthin- 6- one (aervin), 10- $\beta$ - Dglucopyranosyl- oxycanthin- 6-one (aervoside), $\beta$ - carboline- 1- propionic acid and 6- methoxy$\beta$ - carboline- 1- propionic acid (aervolanin) are some of the phytoconstituents isolated from the herb. The plant also contains palmitic acid, $\beta$ sitosterol and alpha-amyrin.

It also has anthelmintic action. The roots of plants are used in the treatment of headache. It is also used as demulcent \& useful in strangury (Ayurveda). It is used in traditional medicine as antidiarrhoeal, diuretic, and in lithiasis. It is valued for cough, as a vermifuge for children, in the treatment of headache, and in arsenic poisoning. The herb is also used in malaria and skin diseases. The plant is reported as anti inflammatory, diuretic in lithiasis ${ }^{2}$, antimicrobial ${ }^{3}$, anti diabetic ${ }^{2}$, antitumour ${ }^{4}$.

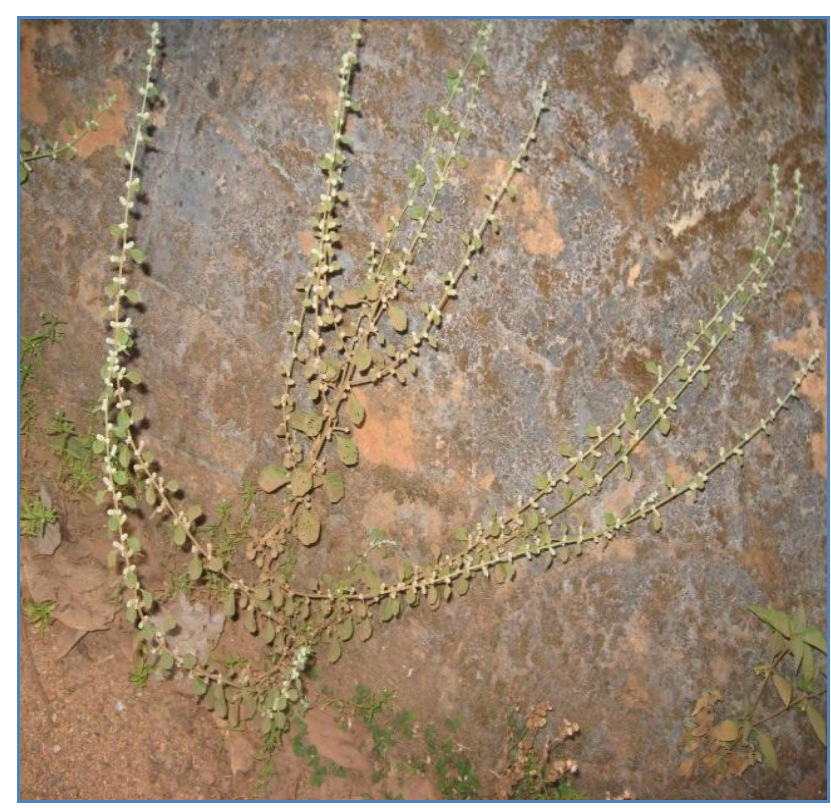

FIG 1: AERVA LANATA (L.)JUSS.EX.SCHULT

Biophytum sensitivum (L.) DC: This herb is commonly known as Lajjalu in Hindi, belonging to Oxalidaceae family, distributed throughout the hotter parts of India as weeds in moist shady places and all over tropical Africa and Asia to the Philippines. It is a very small flowering plant, an annual herb of erect stem, stout or slender, and glabrous. Leaves crowded into a rosette on the top of the stem, petiole is short, and leaflets opposite, on either sides spreading out from a common base, $1 \mathrm{~cm}$ long, 6-12 pairs, oblong in shape and obliquely rounded and apiculate at the apex. Each plant produces five to ten small flowers with yellow petals ${ }^{5}$.

This plant flower (Mukkutty) is an important flower for the people of Kerala. The flower is used in Athapoo, special floral formation that adores courtyards and public places during Onam, the national festival of Kerala. The main constituent present is insulin. The other constituents are two biflavones, cupressuflavone and amentoflavone, three flavonoids, luteolin -7-methyl ether, isoorientin and 3'-methoxyluteolin 7-0-glucoside as well as two acids, 4-caffeoylquinic acid were isolated from the aerial parts of Biophytum sensitivum.

In Ayurveda, this is a tonic, stimulant and in the treatment of stomach ache, diabetes and asthma. It is also used in insomnia, convulsions, cramps, chest-complaints, inflammations, tumors, chronic skin diseases. Decoction is given in asthma and phthisis. Roots decoction is given in lithiasis. The plant is bitter, expectorant, stimulant and tonic. The leaves are diuretic, relieve strangury. The seeds are powdered and applied to wounds. The root in decoction is given in gonorrhea and lithiasis. The crushed whole plant is used in chronic skin troubles. It is eaten to induce sterility in $\operatorname{man}^{6}$. The effect of the leaf extract for the treatment of hyperglycaemic patients was studied on glucose homeostasis in rabbits. The study revealed the insulinotropic effect of Biophytum sensitivum. The anti-inflammatory activity of aqueous and methanol extracts of aerial parts and roots were studied in the carrageenin-induced rat paw oedema model. All the extracts except the 
methanol extracts of aerial parts exhibited antiinflammatory activity.

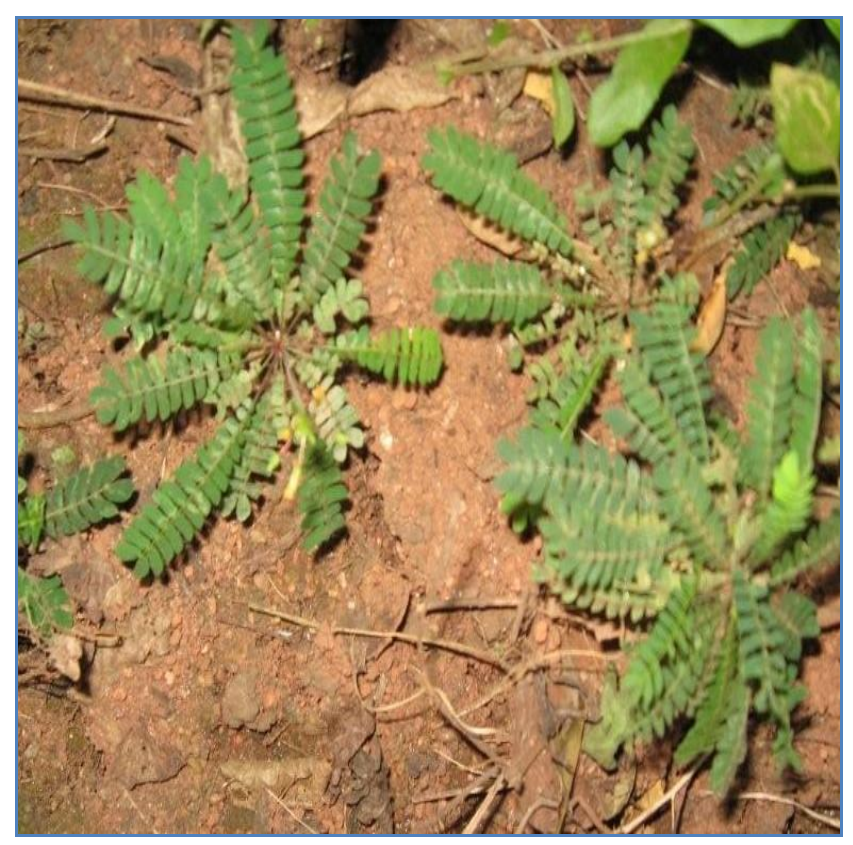

FIG 2: BIOPHYTUM SENSITIVUM (L.) DC

Cynodon dactylon (Linn.) Pers.: This herb is known as Durva, belonging to family Poacea can grow in poor soil. It is a creeping grass growing throughout the country. Bermuda grass or Dhub grass was considered as a sacred grass by the Hindus, and it is still used for worships in temples. In ancient days, the Romans squeezed the juice from the stems and used it as a diuretic and also used to stop bleeding. It grows in open areas where there are frequent disturbances such as grazing, flooding, and fire. The various common names are Bermuda grass, Bahama grass, Devil's grass. The parts used medicinally are the stems and the leaves ${ }^{7}$.

The leaves are narrowly linear or lanceolate and finely acute with $2-10 \mathrm{~cm}$ length and $1.25-3 \mathrm{~mm}$ width. The stem is slender, very smooth and yellowish-green in colour. The roots are cylindrical, cream coloured and upto $4 \mathrm{~mm}$ thick. Bermuda grass is reported to contain cynodin, hydrocyanic acid, and triticin. Phenolic phytotoxins-ferulic, syringic, $p$-coumaric, vanillic, $p$-hydroxybenzoic and O-hydroxyphenyl acetic acids, are reported from the plant. The leaves contain flavone $\mathrm{C}$ glycosides and $\mathrm{a}$ flavonoid sulphate. The grass is a remedy in epitaxis, haematuria, inflammed tumours, whitlows fleshy excrescences, cuts, cystitis, nephritis and in scabies and other skin diseases. Herb is possessing astringent, anticatarrhal, styptic properties.

The Ayurvedic Pharmacopoeia of India describes the dried fibrous root in menorrhagia, metrorrhagia and burning micturation. It is also reported to be antiseptic, demulcent, diuretic, and emollient. A decoction of the root is used to stop bleeding from piles. Internally it is used in the treatment of chronic diarrhoea and dysentery. The leaf juice has also been used in the treatment of hysteria, epilepsy and insanity. The plant is a folk remedy for headache, haemorrhage, hypertension, measles, snake bite, uro-genital disorders warts and wounds.

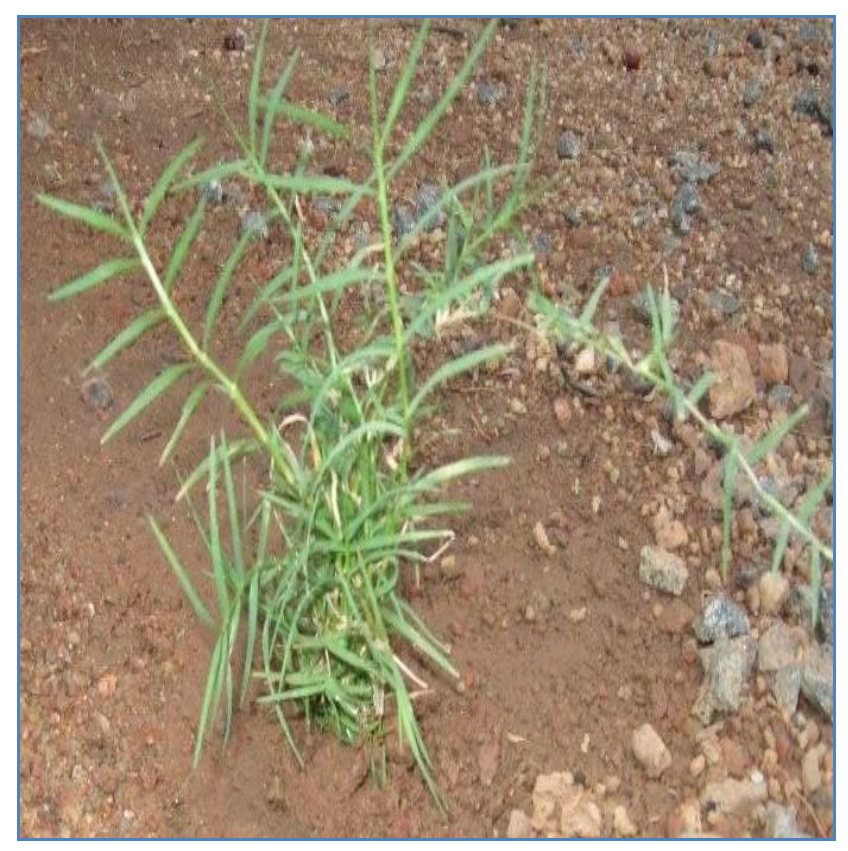

FIG 3: CYNODON DACTYLON (L.) PERS.

Emilia Sonchifolia Dc.: This plant is commonly known as Red Pualele, belonging to Asteraceae; Compositae family. A glabrous slender herb, 30$40 \mathrm{~cm}$ in height. Erect, variously branched. Leaves obovate and flowers purplish in colour. Distributed throughout India, Ceylon, most tropical and sub tropical regions. Whole plant is used medicinally. Also known as Cupid's shaving 
brush. This is found in waste grounds and moist areas. The aerial part of the plant has been reported to contain alkaloids, flavonoids, and terpenes. The aerial parts contain pyrrolizidine alkaloids, senkirkine and doronine. Presence of simiaral, $\beta$-sitosterol, palmitic and triacontannic acids is also reported in the plant ${ }^{8}$. The plant is sudorific, antiseptic, astringent, depurative, diaphoretic, diuretic, expectorant, febrifuge, and ophthalmic. A tea made from the leaves is used in the treatment of dysentery. The juice of the leaves is used in treating eye inflammations, night blindness, cuts and wounds and sore ears. It is used in infantile tympanitis and bowel complaints. Root used as antidiarrhoeal. Leaf used for otitis media under medical supervision.

Fresh juice and methanoic extract of $E$. sonchilfolia leaves reported to possess anti inflammatory and antioxidant activities. The water extract of this plant showed antimicrobial activity. It has been reported that the alcohol extract of this plant (aerial part) has cytotoxicity, as well as anti Ehrlich ascitic carcinoma (EAC) and anti Dalton's lymphoma ascites (DLA) activities in mice.

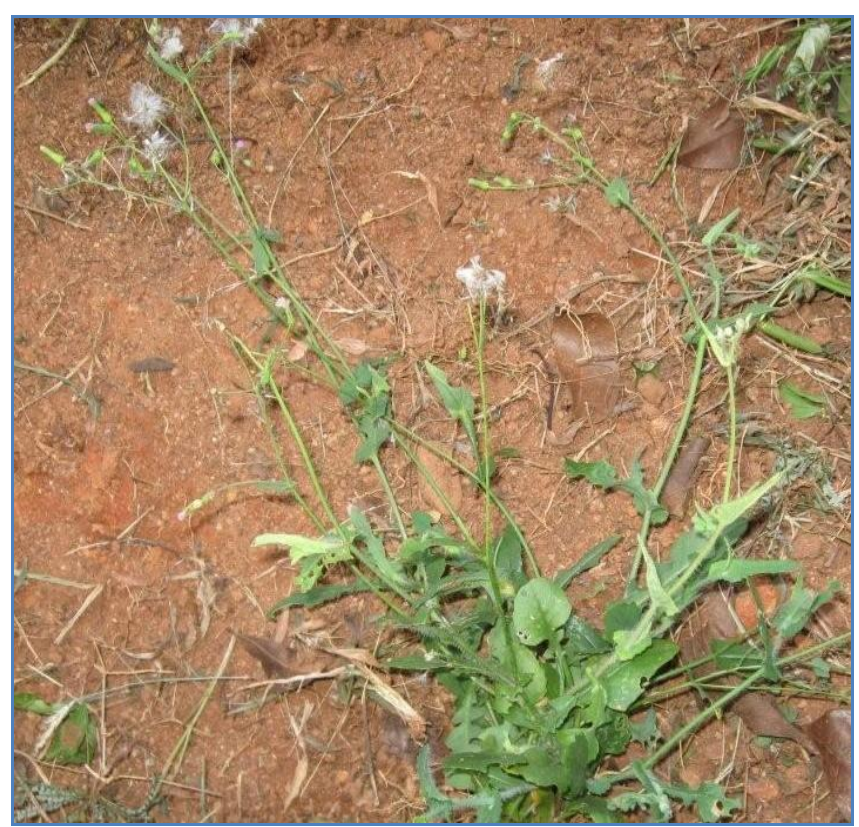

FIG 4: EMILIA SONCHIFOLIA (L.) DC

Eclipta Alba Hassk.: This plant is commonly known as False Daisy belonging to the family
Asteraceae. Erect/ prostrate annual herb distributed throughout India in moist waste lands. The roots are well developed and a number of secondary branches arise from main root, and greyish in colour. Cylindrical stems are dark Green in colour and shows longitudinal ridges. The leaves are $2.2-8.5 \mathrm{~cm}$ long, $1.2-2.3$ $\mathrm{cm}$ wide and usually oblong, lanceolate in shape. Small flower heads contain white, compressed ray florets and yellowish disc florets. Fruits are one seeded achenial cypsela.

In Ayurvedic medicine, the leaf extract is considered to be powerful liver tonic, rejuvenative and especially good for the hair. A black dye obtained from Eclipta alba is also for dyeing hair and tattooing. It also has traditional external uses, like eczema and dermatitis, on the scalp to treat hair loss and the leaves have been used in the treatment of scorpion stings. It is reported to improve hair growth and colour. Coumestan derivatives such as wedelolactone and demethylwedelolactone and norwadelolactone.Thiophene derivatives ecliptal and various dithiemylacetylene esters (I, II, III) reported from roots, saponin compounds like eclalbosaponins I-IV and other common sterols and triterpenoids.

The flavonoids glycoside eg: luteolin-7 0 glucoside and long chain alcohols such as hentriacontanol, 14- heptacosanol have also been reported along with certain alkaloids and polypeptides. The whole plant contains ecliptine, nicotine and stigmasterol. The entire plant contains triterpenes: ecalbatin, echinocystic acid, oleanic acid, ursolic acid, flavone. It is a potential hepatoprotective agent, in jaundice and in conditions of liver and spleen enlargement, Hypotensive and myocardial depressant activity, anti-inflammatory, abortion and miscarriage, piles, insect bites, swellings and other skin diseases.

Dried aerial parts are used as a purgative, emetic, cholagogue, antiasthmatic. Leaves are used to treat epilepsy in India. Roots are used for insanity. The entire plant is used for 
tuberculosis and as haemostatic. Oil soluble extracts helps in promotion of growth and colour of hairs. Its hair oil preparations are used as a scalp tonic in India ${ }^{9}$. Coumestans are known to possess estrogenic activity.

Wedelolactone possesses a wide range of biological activities and is used for the treatment of hepatitis and cirrhosis, as an antibacterial, anti-haemorrhagic, as an antidote for snake venom. The hydroalcoholic extract of the dried leaf reported analgesic activity, when administered intragastrically in mouse 100 $\mathrm{mg} / \mathrm{kg}$. The chloroform and methanol extract of the dried leaf $1 \mathrm{gm} / \mathrm{ml}$ showed antibacterial activity against Bacillus subtilis, Escherichia coli, Pseudomonas aeruginosa, and Staphylococcus aureus. Various Other biological activities which have been reported in the literature for the extracts of $E$. alba: hepatoprotective, antiviral, antirheumatic, molluscicidal, antimalarial and antifertility.

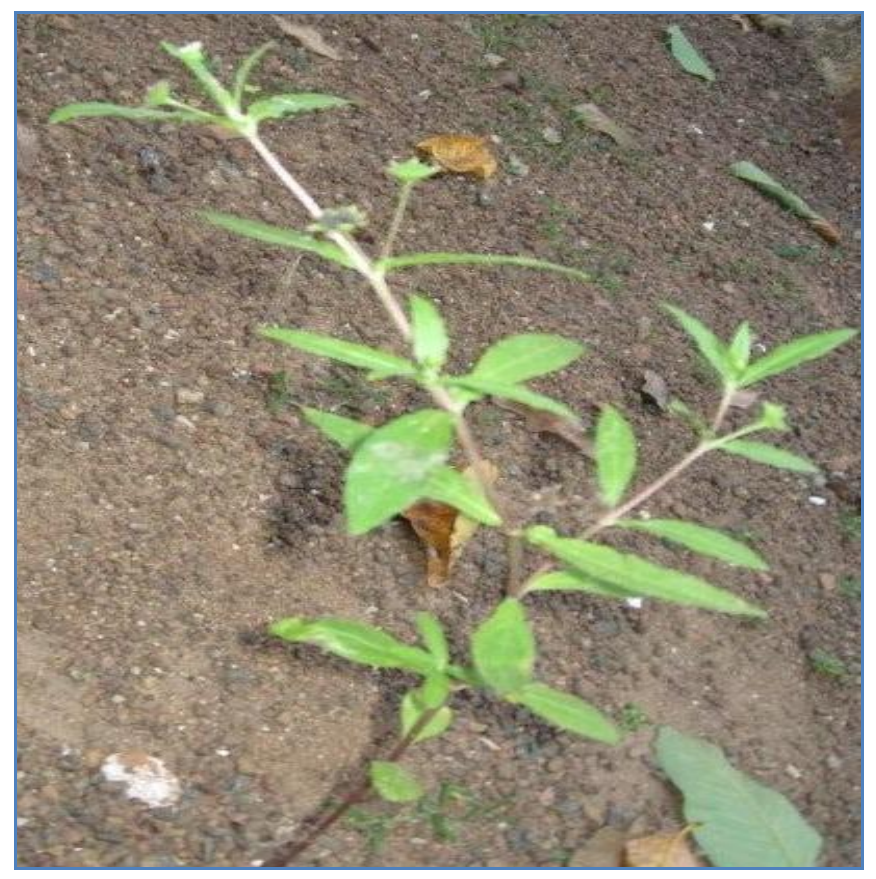

FIG 5: ECLIPTA ALBA (L.) MANT

Ipomoea sepiaria koen. Ex Roxb.: This plant known as Lakshmana in Sanskrit belongs to convolvulaceae family. Distributed throughout greater part of India. Whole plant is used medicinally. This is a perennial vine. Annual, stems very long and slender, often purplish, twining, glabrous. Leaves are simple, alternate, entire, petiolate, cordate, blotched with brownish or purplish patches towards the centre and thin; flowers pale purple or pink, funnel shaped, in umbellate axillary cymes. Fruits ovoid capsules, 2-4 seeded, seeds grey colored covered over silky pubescence.

Ipomoea resin, the seeds contain nonergoline type indole alkaloids, ipobscurine A \& B, and a serotonin alkaloid Ipobscurines $C^{10}$. Juice of the plant is used as deobstruent, diuretic, hypotensive, uterine tonic, antidote to arsenic poisoning. Seeds used as cardiac depressant, hypotensive, spasmolytic. Plant is also used in the treatment of sterility in women, urinary retention, constipation, gynaecological disorders. The plant is reported to show aphidicidal activity and appeared to be useful as pesticides.

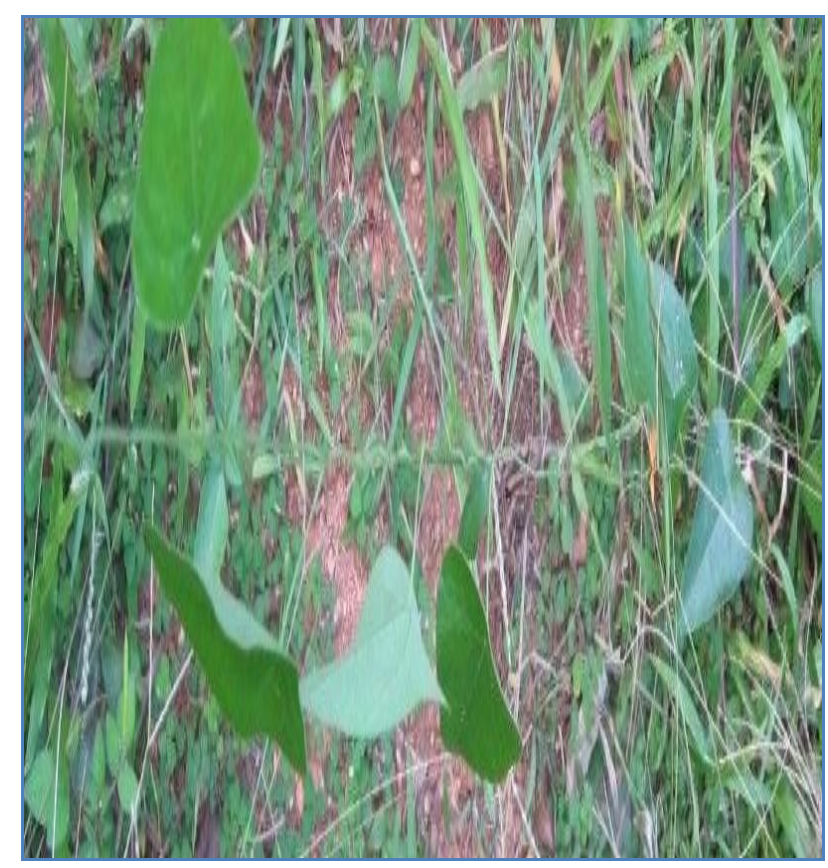

FIG 6: IPOMOEA SEPIARIA KOEN. EX ROXB.

Cardiospermum halicacabum Linn.: Plants common names are Balloon vine, Heartseed vine, love in a puff and Winter Cherry. A plant of Sapindacea family wide spread in tropical and 
subtropical Asia and Africa. A climbing tendril bearing herb with wiry stem throughout the plains of India. Branches slender and leaves deltoid, 2-ternate, petioles $2-3.8 \mathrm{~cm}$ long and flowers are white. Seeds are globose. In India, leaves are commonly consumed as leafy vegetable.

It is known to contain saponin, quebrachitol, apigenin, proanthocyanidin and stigmasterol. The seeds show the presence of luteolin-7-o-glucuronide, $\beta$-sitosterol- $\quad \beta$-Dgalactoside. The leaves contain (+)pinitol,apigenin and its 7-O-glucuronides, chrysoeriol and luteolin. The roots contain $\beta$ sitosterol. The leaves contain an alkaloid, oxalic acid and amino acids. The root is considered diaphoretic, diuretic, and aperient. The fried leaves are considered emmenagogue. The leaves and stem are used against common cold and angina. The leaf paste is applied on domestic animals to kill lice and other insects. It is used in the treatment of rheumatism, lumbago, skeletal fractures, nervous diseases, amenorrhoea, haemorrhoids, and erysipelas, emetic, laxative, rubefacient and stomachic.

The herb is used in hair oils for treating dandruff, alopecia and for darkening hair. The plant extracts showed marked insecticidal effects as ovicide and larvicide for Musca domestica Linn. and as larvicide for Philosamia ricini (Boisd.) Alcoholic extract of the plant showed antisickling and antiarthritic activity. In the pharmacological validation of this plant, the toxicological evaluation of $C$. halicacabum revealed that the drug is safe and is not toxic upto $40 \mathrm{~g} / \mathrm{kg}$ in rats. The plant extract showed significant analgesic and anti-inflammatory activity and sedative effect on CNS. The drug also showed (transient) vasodepressant activity. Seeds have positive anabolic activity and increase body weight by inducing a positive nitrogen balance. The alkaloid fraction from the seeds showed hypotensive activities and cardiac inhibition in anaesthetized dogs; blocked spasmogenic effects of acetylcholine, histamine on guinea pig ileum, biphasic action on frog rectus abdominus muscle. The seeds also showed antibacterial activity.

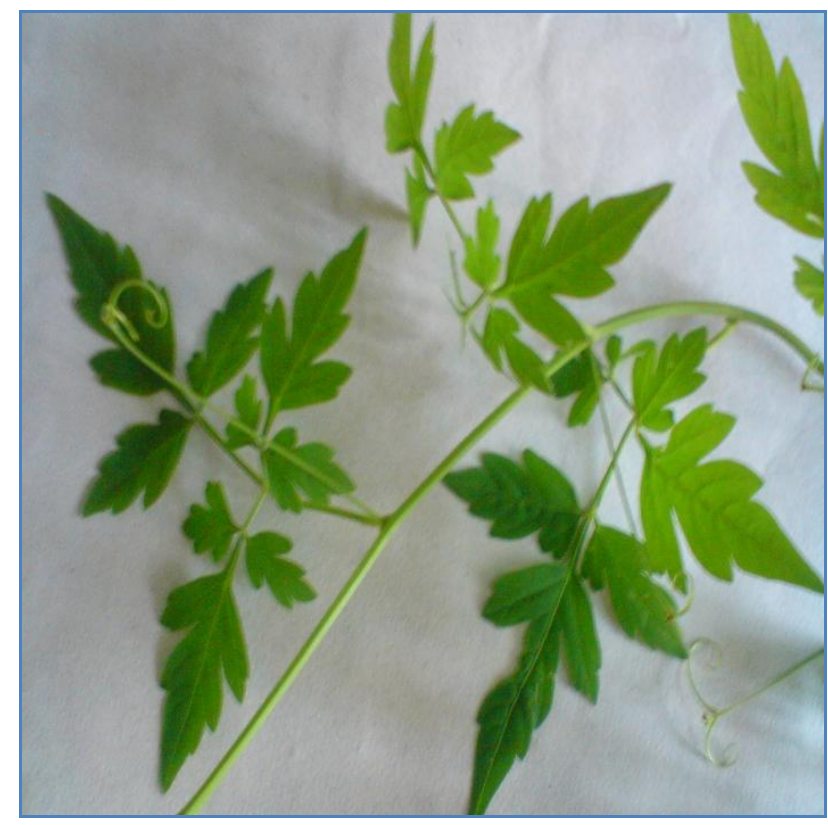

FIG 7: CARDIOSPERMUM HALICACABUM L.

Evolvulus alsinoides Linn.: In Sanskrit, this plant is known as 'Vishnu's step' and was used in worship belongs to Convolvulaceae family. The plant was used as a remedy for dysentery and was used to enhance intelligence and improve memory. This is widely distributed in tropical and subtropical regions throughout the world. It grows as a weed in open and grassy places throughout India. It is a small perennial herb with small woody root stock. The leaves are alternate, simple, elliptic-oblong in shape. The flowers are light blue in colour, solitary or sometimes in pairs. Fruits are globose, four valved drooping capsules.

The plant contains beta-sitosterol, stearic, oleic, linoleic acids, pentatriacontane and triacontane. Betane, sterols, tannins, carbohydrates, proteins and alkaloid namely evoline are present in the whole plant. The whole plant is used for various ailments. The plant is bitter, acrid, febrifuge, aphrodisiac, anthelmintic, expectorant and useful in bronchitis, brain tonic, an aid in conception, astringent, antidysenteric and asthma. It is also 
useful in epilepsy, forgetfulness, falling and greying of hair, intermittent fevers and general debility. It is also one of the ingredients of the polyherbal formulation, Bramhi Grita. Used in nervine affections (epilepsy, insanity, spermatorrhoea), and duodenal ulcers, also for uterine affections uterine bleeding and internal haemorrhages. A decoction of the herb is given as a blood purifier. It is reported to show powerful stimulant activity on respiration and blood pressure (possibly analeptic). Aqueous extract of the petal showed antifungal property.

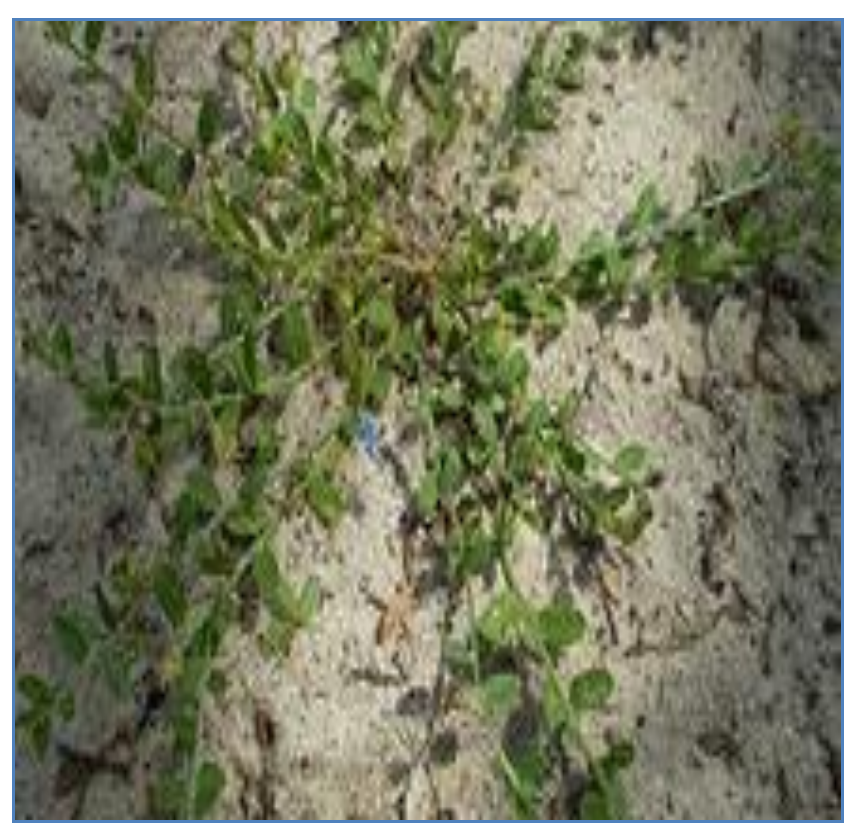

FIG 8: EVOLVULUS ALSINOIDES (L.) L. VAR. ALSINOIDES

Vernonia cinerea (Linn.) Less: This plant is commonly called as ash-coloured fleabane belonging to the family Asteraceae, Sahadevi in Hindi and puvvamkurunnila in Malayalam. It is distributed throughout India, as a weed on roadsides and open places. An erect annual herb, $12-75 \mathrm{~cm}$ in height with cylindrical branched stem, leaves is variable in shape and flowers are many pinkish violet in small heads. Regarding the history of the plant, it was mentioned in Sanskrit texts as being present in northern, western and southern India. The chief constituents are the triterpenes. Aerial parts gave luteolin- monobeta- D- glucopyranoside. Whole plant gave triterpene compoundsbetaamyrin acetate, lupeol acetate, betaamyrin and lupeol; sterols- beta- sitosterol, stigmasterol and alpha-spinasterol; phenolic resin and potassium chloride. Parts that were used include the flower (treatment of conjunctivitis), seeds (used as anthelmintic), root (dropsy), and juice (piles).

The whole plant is also considered to promote perspiration in febrile condition. The plant is anthelmintic, antibacterial, antiviral, antifungal, anti-inflammatory, diuretic, and stomachic. The roots are useful in diarrhoea, cough, inflammations, skin diseases, leprosy, renal and vesical calculi. The leaves are useful in humid herpes, eczema, ring worm, guineaworms, and elephantiasis. The flowers are used in conjunctivitis, vitiated condition of vata and fever. The seeds are useful in roundworms, threadworms, cough, flatulence, leucoderma, psoriasis, chronic skin disease; the plant is used as anticancer, febrifuge, diaphoretic (infusion of herb, combined with quinine, is used against malaria). Used as a specific herb for leucorrhoea, dysuria, spasm of bladder, strangury and for haematological disorders, as a blood purifier and styptic, also used in asthma.

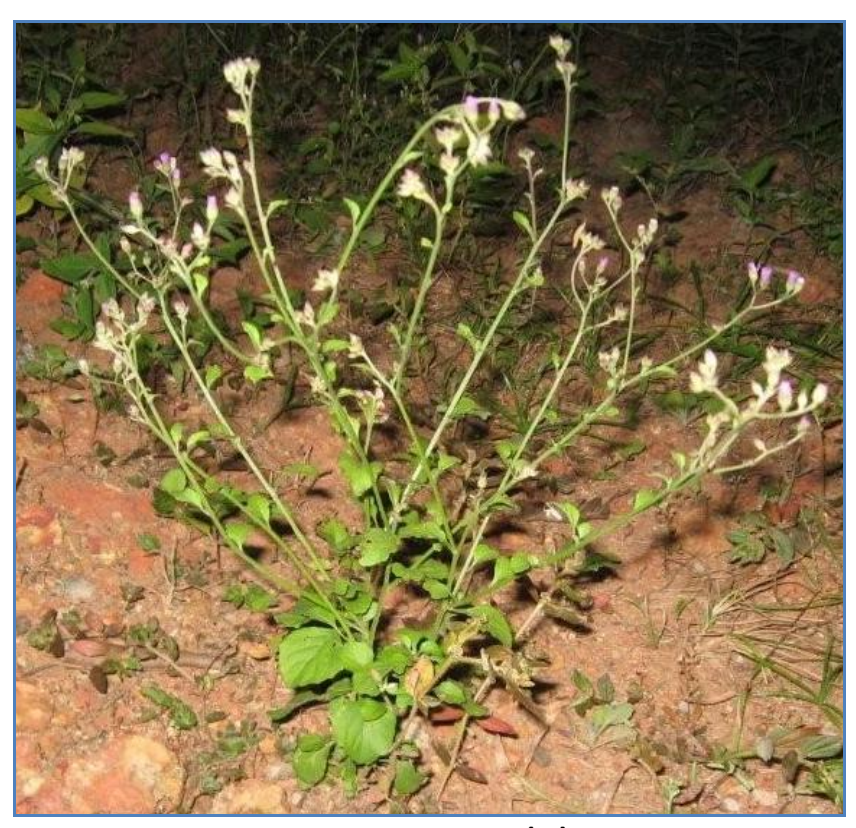

FIG 9: VERNONIA CINEREA (L.) LESS.

Seeds used as antiflatulent, antispasmodic; used in dysuria, decoction used 
for colic. The Ayurvedic Pharmacopoeia of India recommends the plant in intermittent fever, filariasis, pityriasis versicolour (tinea versicolor), blisters, boils, vaginal discharges and in cases of psychoneurosis. The water soluble fraction of the methanol extract of the defatted dried ground whole plant of Vernonia cinerea showed significant diuretic activity in rats comparable to lasix a known diuretic.

Curculigo orchioides Gaetrn.: This plant is known as Musali in Sanskrit and Kali Musali in Hindi belonging to family Amaryllidaceae, is an important Ayurvedic as well as Unani drug. It has been recorded occurring in the subtropical Himalayas from Kumaon eastwards ascending to 1800 meters, the Hhasia hills, Bengal, assam, Konkan, the western Peninsula and madras extending South as far as cape comorin. In Malayalam, this plant is known as nilappana. Kali Musali grows as forest herb. In many parts of India, due to it's over exploitation, kali musali is becoming rare in occurrence.

Leaves sessile or petiolate linear or linear-lanceolate and root stock stout. Flowers are bright yellow in colour. A new orcino; glucoside, orcinol-1- beta D- apiofuranosyl betaD glucopyranoside was isolated. Orcinol glucoside, curculigoside, curculigoside B \&C, Syringic acid, 2, 6 dimethoxyl benzoic acid. The rhizome contains saponins (curculigosaponin C and F) sapogenins; phenolic glycosides, a triterpene alcohol; a pentacyclic triterpene, an aliphatic compound, hentriacontanol, sitosterol, stigmasterol, cycloartenol and sucrose. A peptide, Curculin C, containing amino acids, has been isolated from the fruit. It is present in several drug formulations used in the treatment of menorrhagia and other gynaecological problems. Since generations, it is in used as folk medicine. The root is bitter, appetizer, nervine, adaptogenic, sedative, anticonvulsive, androgenic and anti-inflammatory. It is also used in Jaundice, urinary disorders and skin diseases, useful in piles, fatigue, diseases of the blood.
The rhizome is used for asthma, diarrhoea, and gonorrhea, demulcent and diuretic, tonifying kidney and for strengthening muscles and bones. According to Ayurveda, root is heating, aphrodisiac, appetizer, useful in the treatment of piles, fatigue, blood related disorders. According to Unani system of medicine, root is carminative, tonic, aphrodisiac, antipyretic and useful in bronchitis, ophthalmic, indigestion, vomiting.

In traditional Chinese medicine, dried rhizome, containing curculigoside is used as a tonic for its immunological and protective property. In Indian medicine, powdered rhizomes with milk are taken as a restorative tonic, also for sexual debility. Curculigosaponin C and $F$ promoted proliferation of spleen lymphocytes very significantly; $F$ and $G$ increased the weight of the thymus in vitro in mice. Alcoholic extract of the plant exhibited hypoglycaemic property. The plant is reported to possess hepatoprotective, immunostimulant and antioxidant activities.

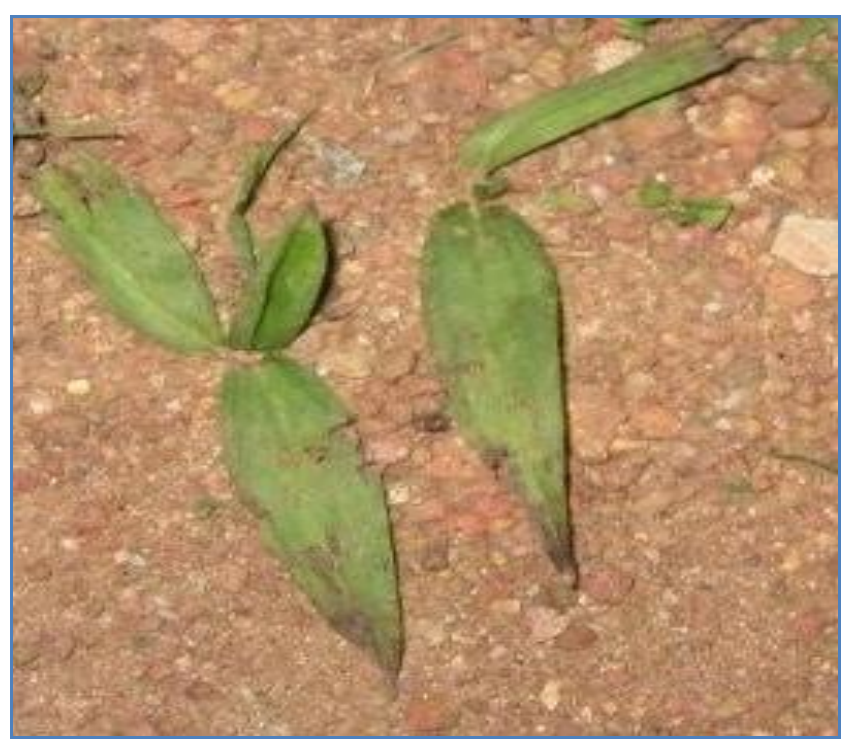

FIG 10: CURCULIGO ORCHIOIDES GAERTN

CONCLUSION: The therapeutic potential of these ten sacred plants are unlimited and not explored properly to cure various illness. Research and development must be encouraged for developing new drug molecules from these plants. The detailed investigation of its 
standardization, pharmacological activity, toxicity and clinical trials may help to develop new drugs for controlling various diseases. The global scenario has shown a great increase in phytomedicine research. So, the drug development from these plants has tremendous scope in the future. Some of the research activities have been carried out on these plants during the past few decades which give sufficient motivation among the scientist community in exploring more information about these sacred plants. A research and development programme should be undertaken on Dasapushpam for their potential in economic and therapeutic utilization. Appropriate measures for conservation can be executed since some of the plants like Kali musali, an Ayurvedic Dasapushpam and a rejuvenating and aphrodisiac drug is on the verge of extinction. So, those plants need to be conserved and cultivated.

\section{REFERENCES:}

1. The wealth of India: First Supplementary Series. NISC CSIR, India, Vol-1, 2000: A-92.

2. Vetrichelvan $T$, Jegadeesan $M$, Palaniappan M S, Murali N P, Sasikumar K : Diuretic and anti-inflammatory activities of Aerva lanata in rats. Indian Journal of Pharmaceutical Sciences 2000; 4:300-305.

3. Dulaly C, Abu Sayeed, Anwarul Islam, Shah Alam Bhuiyan M, Astaq Mohal Khan G R M : Antimicrobial and cytotoxicity of Aerva lanata. Fitoterapia 2002; 73:92-94.

4. Nevin K G, Vijayammal P L: Effect of Aerva lanata on solid tumour induced by DLA cells in mice. Fitoterapia 2003; 74:578-582.

5. Kirtikar K R, Basu B D: Indian medicinal plants. International book distributors, Dehradun, India, Edition 3,Vol. ,2005:

6. The wealth of India: First Supplement Series. NISC CSIR, India, Vol-1, 2000 : A-Ci:140.

7. Ayurvedic pharmacopoeia. Controller of Publications, Delhi, Edition 1, Vol-3, 2001: 47-48.

8. The wealth of India: First Supplement Series. NISC CSIR, India, Vol-3,2002 : D-1 : 79.

9. Ayurvedic Pharmacopoeia. Controller of Publications, Delhi, Edition 1, Vol-2, 1999:21-24.

10. The wealth of India: Second Supplement Series. NISC CSIR,India,Vol-2,2007:G-Ph:101. 